\title{
Quadriceps weakness in knee osteoarthritis: the effect on pain and disability
}

\author{
Sheila C O’Reilly, Adrian Jones, Ken R Muir, Michael Doherty
}

\begin{abstract}
Objectives-(1) To determine the importance of quadriceps strength, structural change, and psychological status in terms of knee pain in the community. (2) To determine the relative importance of quadriceps function, structural change, and psychological status with respect to disability in subjects with knee pain.

Methods-300 men and women with pain and 300 controls without pain (aged 40-79) were seen. Isometric quadriceps strength (MVC) was measured and muscle activation was assessed by twitch superimposition. Disability (Western Ontario McMaster Osteoarthritis Index (WOMAC)) and anxiety and depression were assessed (Hospital Anxiety and Depression Index (HAD)). Radiographs were obtained of the tibiofemoral and patellofemoral joints and total score for osteophyte, narrowing, and sclerosis calculated for each knee.
\end{abstract}

Results-Subjects with knee pain had lower voluntary quadriceps strength than those without pain $(p<0.005)$. Quadriceps activation was also lower $(p<0.005)$, but did not fully explain the reduction in strength. When analysed by multiple logistic regression: quadriceps strength (odds ratio 18.8, CI 4.8, 74.1 for $M V C \leqslant 10$ kgF); depression (odds ratio 2.4, CI 1.0, 5.5 for HAD score $\geqslant 8$ ); and radiographic change (odds ratio 4.1, CI $1.9,8.6$ for radiographic score $\geqslant 4$ ) were independently associated with pain. In those with knee pain, disability was independently associated with quadriceps strength (odds ratio 8.2 , CI $1.5,44.4$ for $\mathrm{MVC} \leqslant 10 \mathrm{kgF}$ ) and depression (odds ratio 6.2, CI 2.1, 18.0 for HAD score $\geqslant 8$ ); but not with radiographic score.

Conclusions-Quadriceps strength is strongly associated with knee pain and disability in the community, even when activation and psychological factors are taken into account. This has important therapeutic implications.

(Ann Rheum Dis 1998;57:588-594)

Osteoarthritis (OA) is a common disease associated with significant morbidity. ${ }^{1-3}$ This is particularly apparent at the knee joint, one of the commonest sites to be affected. As prevalence of $\mathrm{OA}$ increases with age and aging is associated with decreasing physiological function, the combination has major health implications. ${ }^{4}$ Symptoms cannot, however, be predicted merely by the degree of structural damage. ${ }^{5}$ Although risk factors for structurally defined OA such as obesity, occupation, and sex are well established, ${ }^{6-8}$ the determinants of pain and disability are less clear. ${ }^{9}$

Recent attention has focused on the quadriceps mechanism. Quadriceps strength declines with age, ${ }^{1011}$ with some evidence to suggest subsequent functional impairment. ${ }^{12}$ The association between strength and knee $\mathrm{OA}$ is less certain. Two small studies on hospital referred patients suggest there may be a link between quadriceps weakness and disability ${ }^{13}$ and there is some evidence for a similar relation in the community. ${ }^{15}$ To date such studies have only assessed voluntary strength. As psychological factors are associated with pain and disability in knee OA, ${ }^{16}$ it is possible that the association between symptoms and knee pain is confounded by poor voluntary effort. Incomplete muscle activation may also result from arthrogenous or reflex muscle inhibition. ${ }^{17}$ This has been reported in acute trauma and effusions ${ }^{18}$ but has not been fully explored in terms of knee OA or chronic knee pain. ${ }^{19}$

The aim of this study was to examine the associations between quadriceps strength and quadriceps activation with knee pain and disability in a community derived population. In addition we wanted to assess the relative importance of quadriceps strength, radiological severity, and psychological status.

\section{Methods}

SUBJECTS

A nested case-control design was used with subjects derived from a postal survey concerned with knee pain. This survey, which has been described elsewhere ${ }^{20}$ was conducted on 4057 men and women aged 40-79, registered at two general practices in Nottingham. A response rate of $81.9 \%$ was achieved following a reminder. Knee pain was defined as a "yes" response to both parts of the question: "Have you ever had pain in or around the knee on most days for at least a month? If so, have you experienced any pain within the last year?" The suitability of this question as a screen for presence of pain has been previously examined. ${ }^{20}$ The prevalence of knee pain was $28.7 \%$. Subjects with knee pain were randomly selected and contacted by telephone. In view of an unavoidable delay between sending out the postal questionnaire and recruiting for this study, current knee pain was ascertained by the following question. "Have you had any pain within the last week?"

Subjects answering "no" were excluded at this stage. A total of 300 knee pain positive subjects were recruited together with an equal 
Table 1 Comparison of demographic details of cases (knee pain positive) and controls (knee pain negative) with the corresponding total population from postal survey. Means and standard deviations are quoted. Physical functions scores are derived from the SF-36 Health Status Questionnaire

\begin{tabular}{|c|c|c|c|c|c|c|c|c|}
\hline & \multicolumn{4}{|c|}{ Knee pain positive } & \multicolumn{4}{|c|}{ Knee pain negative } \\
\hline & $\begin{array}{l}\text { Cases } \\
\text { Men }\end{array}$ & Women & $\begin{array}{l}\text { Total population } \\
\text { Men }\end{array}$ & Women & $\begin{array}{l}\text { Controls } \\
\text { Men }\end{array}$ & Women & $\begin{array}{l}\text { Total population } \\
\text { Men }\end{array}$ & Women \\
\hline Age & $61.4(10.8)$ & $61.0(11.2)$ & $56.8(10.6)$ & $58.5(11.4)$ & $61.3(10.8)$ & $60.5(10.7)$ & $55.3(10.2)$ & $55.6(11.0)$ \\
\hline Body mass index & $27.6(3.9)$ & $27.6(5.6)$ & $26.5(3.7)$ & $27.0(5.3)$ & $26.2(3.5)$ & $25.3(3.8)$ & $25.7(3.3)$ & $24.8(3.9)$ \\
\hline Physical function score & $52.5(28.2)$ & $52.6(24.7)$ & $63.4(31.1)$ & $56.6(29.6)$ & $76.7(26.7)$ & $80.2(20.8)$ & $82.2(24.9)$ & $81.1(23.2)$ \\
\hline
\end{tabular}

number of subjects without pain. Controls were matched to cases by sex and by age to within five years. Controls who had developed knee pain since the postal survey were excluded.

All assessments with the exception of radiography were undertaken at the respective general practice surgery.

The study was approved by the local ethics committee.

\section{PAIN AND DISABILITY}

Severity of pain was assessed in subjects with knee pain using the pain section of WOMAC OA index. ${ }^{21}$ This contains five questions concerning severity of pain during various activities, each scored $0-4$. Subjects were asked to grade level of pain overall rather than separately for each knee. Scores were summated to produce a global pain score from $0-16$, with higher scores indicating more severe pain.

Disability was primarily assessed by the physical function section of WOMAC. ${ }^{21}$ This has 17 questions and scores were summated to produce a global function score, ranging from 0-68, with higher scores indicating more disability. Factors associated with disability were examined separately in the knee pain positive and negative groups, as knee pain, not disability, was used for case definition. Where a categorical assessment was required, disability was defined as a score higher than the median value for that group. Additional data on physical function were derived from the Anglicised SF-36 Health Status Questionnaire. ${ }^{22}$ This contains 10 questions on function, with overall

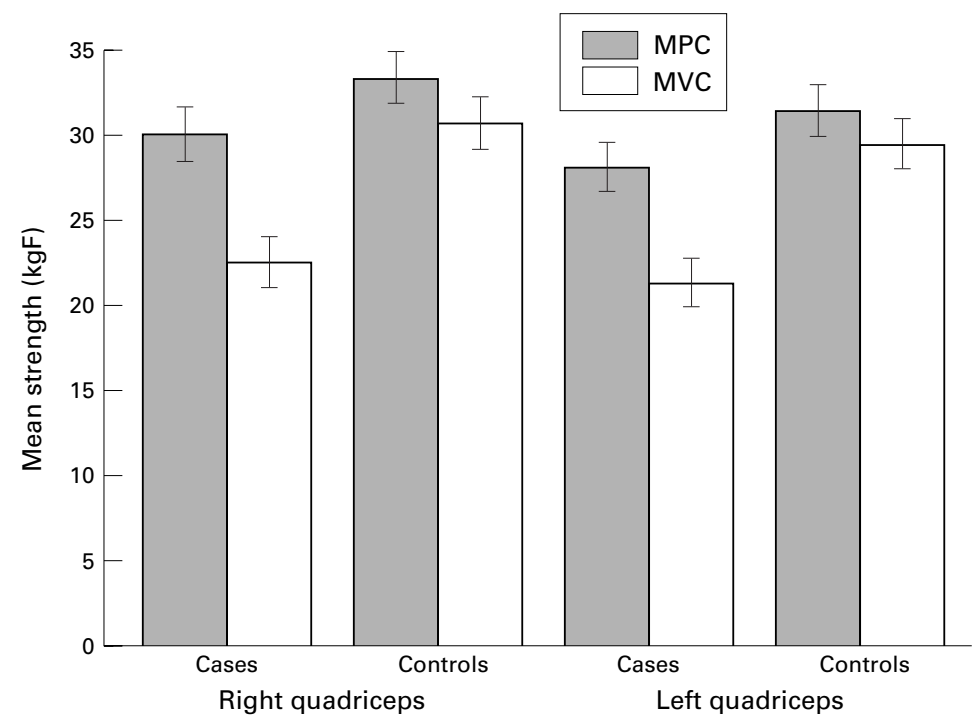

Figure 1 Mean maximum voluntary strength (MVC) and mean predicted strength (MPC) for right and left quadriceps in cases (subjects with knee pain) and controls (subjects without knee pain). Error bars denote 95\% confidence intervals. score ranging from $0-100$ where higher scores indicate "better" function. Levels below the median were taken to indicate disability.

PSYCHOLOGICAL FACTORS

Anxiety and depression were assessed using the Hospital Anxiety and Depression Scale (HAD). Scales for anxiety and depression are scored from $0-21$, with scores of 8 or above indicating tendency towards anxiety or depression. ${ }^{23}$

\section{QUADRICEPS STRENGTH AND ACTIVATION}

Quadriceps strength was measured with a modified Tornvall chair. ${ }^{24}$ Subjects were seated with hip and knee flexed to $90^{\circ}$ and the pelvis secured. A strap placed above the right medial malleolus was attached by means of an inextensible chain to a strain gauge $( \pm 50 \mathrm{kgF}$ TKA load cell, Techni Measure, Studley). This was connected to an A-D converter (TML model TD-91M, Tokyo Sokki Kenkyujo Co Ltd, Japan), with the final output read onto a Xyt chart recorder (BD92, Kipp and Zonen Delft BD, the Netherlands). After explanation and demonstration, the highest of three attempts was taken as the maximum voluntary contraction (MVC). To measure quadriceps activation, the technique of twitch superimposition was used. ${ }^{25}$ Electrodes were placed on the anterior thigh, and stimulation achieved using a high voltage stimulator (DS7-H, Digitimer Ltd, Welwyn Garden City). Duration of stimulation was $50 \mathrm{~ms}$, amplitude was $1 \mathrm{~A}$, and voltage was adjusted to stimulate approximately $20 \%$ of maximum strength. After three baseline twitches, three further twitches were applied while the subject was maximally contracting the quadriceps. After a rest period, the procedure was repeated. The entire procedure was then performed using the left leg. To calculate maximal predicted contraction

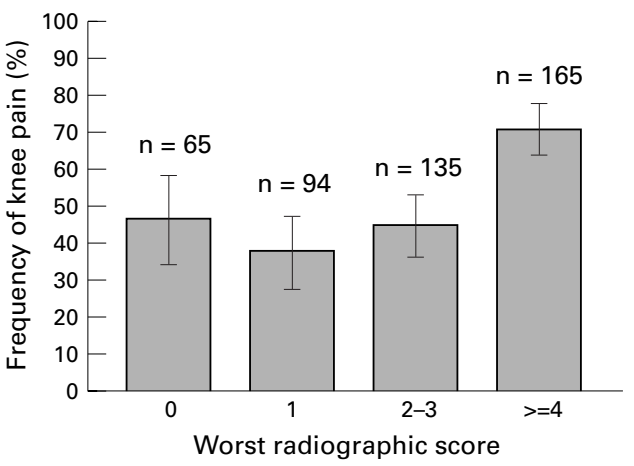

Figure 2 Percentage of subjects with knee pain by level of radiographic score (highest score for each subject from right or left knee). Error bars represent $95 \%$ confidence intervals. $n=$ total number of subjects in each group. 


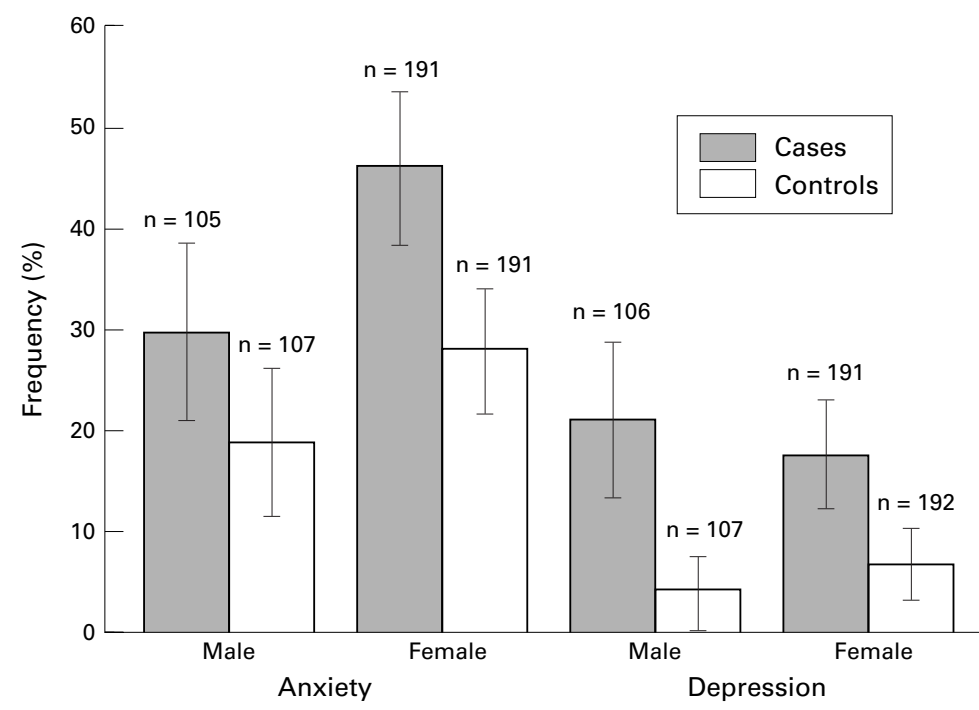

Figure 3 Prevalence of anxiety and depression (HAD score $\geqslant 8$ ) for men and women with knee pain (cases) and without knee pain (controls). Errors bars represent $95 \%$ confidence intervals. $n=$ total number of subjects in each group.

Table 2 Association of knee pain with anxiety, depression, voluntary quadriceps strength (MVC), quadriceps activation, and radiographic score. Odds ratios have been calculated using logistic regression and are adjusted for age, sex, and BMI in addition to the variables shown. For bilateral variables, the worst value from either limb has been used in analysis

\begin{tabular}{|c|c|c|c|c|}
\hline & \multicolumn{2}{|l|}{ Knee pain } & \multirow{2}{*}{$\begin{array}{l}\text { Odds } \\
\text { ratio }\end{array}$} & \multirow{2}{*}{$\begin{array}{l}95 \% \text { Confidence } \\
\text { intervals }\end{array}$} \\
\hline & yes (\%) & no (\%) & & \\
\hline \multicolumn{5}{|l|}{ Anxiety } \\
\hline HAD score $<8$ & $89(48.4)$ & $95(51.6)$ & 1 & \\
\hline HAD score $\geqslant 8$ & $89(65.0)$ & $48(35.0)$ & 1.43 & $0.85,2.40$ \\
\hline \multicolumn{5}{|l|}{ Depression } \\
\hline HAD score $<8$ & $139(47.1)$ & $156(52.9)$ & 1 & $\star$ \\
\hline HAD score $\geqslant 8$ & $90(61.2)$ & $57(38.8)$ & 2.36 & $1.01,5.54$ \\
\hline \multicolumn{5}{|l|}{ MVC $(\mathrm{kgF})$} \\
\hline$>40$ & $8(15.7)$ & $43(84.3)$ & 1 & $\star$ \\
\hline $30-40$ & $52(37.4)$ & $87(62.6)$ & 1.49 & $0.56,3.96$ \\
\hline $20-30$ & $84(55.3)$ & $68(44.7)$ & 3.17 & $1.22,8.26$ \\
\hline $10-20$ & $44(68.7)$ & $21(31.3)$ & 7.10 & $2.43,20.68$ \\
\hline$\leqslant 10$ & $25(69.4)$ & $11(30.6)$ & 18.83 & $4.79,74.08$ \\
\hline \multicolumn{5}{|l|}{ Activation (\%) } \\
\hline$>100$ & $37(27.0)$ & $100(73.0)$ & 1 & $\star$ \\
\hline $91-100$ & $82(51.3)$ & $78(48.8)$ & 1.74 & $0.80,3.77$ \\
\hline $71-90$ & $47(60.3)$ & $31(39.7)$ & 1.66 & $0.83,3.32$ \\
\hline$\leqslant 70$ & $47(70.1)$ & $20(29.9)$ & 2.27 & $1.01,5.08$ \\
\hline \multicolumn{5}{|l|}{ Radiographic score } \\
\hline 0 & $29(45.3)$ & $35(54.7)$ & 1 & $\star$ \\
\hline 1 & $34(37.4)$ & $57(62.6)$ & 0.77 & $0.36,1.65$ \\
\hline $2-3$ & $56(43.1)$ & $74(56.9)$ & 1.26 & $0.62,2.54$ \\
\hline$\geqslant 4$ & $110(70.1)$ & $47(29.9)$ & 4.07 & $1.93,8.61$ \\
\hline
\end{tabular}

${ }^{\star}$ Denotes a significant trend test $(\mathrm{p}<0.05)$.

(MPC), each set of three baseline twitches was averaged and this value was used to calculate MPC for each superimposed twitch and corresponding contraction. These six values were averaged and percentage activation was then calculated using the original value for maximum voluntary contraction. ${ }^{26}$

\section{RADIOGRAPHY}

All radiography was standardised and undertaken at the City Hospital, Nottingham. Anteroposterior weightbearing views $(55 \mathrm{kV}, 8$ mAs, FSD $100 \mathrm{~cm}$ ) of the tibiofemoral (TF) joint and skyline views of the patellofemoral (PF) joint $\left(30^{\circ}\right.$ of flexion, $60 \mathrm{kV}, 10 \mathrm{mAs}, \mathrm{FSD}$ $100 \mathrm{~cm}$ ) were taken. A total of 459 complete sets of films were obtained. Radiographs were read blind to knee pain status by one observer and individual features in each compartment graded using a standard atlas. ${ }^{27}$ Osteophyte and joint space narrowing were graded $(0-3)$ for the lateral and medial $\mathrm{TF}$ compartments and $\mathrm{PF}$ compartment. Sclerosis was graded $(0-1)$ for the TF joint overall and the PF joint. A total OA score (0-20) was subsequently calculated for each knee. In addition, grades for maximum osteophyte and joint space narrowing (0-3) were assigned to each subject.

To assess intraobserver variability, 40 sets of films were read on two occasions one week apart. Measurement of agreement for each feature was assessed by calculating an unweighted $\kappa$ coefficient.

\section{STATISTICAL ANALYSIS}

All statistical analysis was performed using SPSS for Windows 6.0 (SPSS Inc). Variables with left and right data (muscle strength, activation, radiographic score) were analysed as the worst value for each subject. Unpaired Student $t$ tests were used to compare mean values. Multivariate analysis of associations with pain were examined using unmatched logistic regression; odds ratios for pain together with 95\% confidence intervals are presented. Significant trend tests $(\mathrm{p}<0.05)$ based on continuous data are quoted. Continuous variables, such as muscle strength, activation, and radiographic score were transformed into categories with one category used as the indicator variable. This was done to satisfy test assumptions and to allow comparison with previously published data. To examine associations with severity of pain within the knee pain positive group, multivariate analysis using linear regression was performed.

Associations with disability have been determined separately in knee pain positive and negative groups. In the knee pain positive group disability has been examined both as a categorical variable (defined as a WOMAC score higher than the median for the group) and as a continuous variable. In the knee pain negative group SF-36 physical function (score lower than the median value for the group) was used to define disability.

\section{Results}

\section{SUBJECTS}

A total of 474 subjects with knee pain were contacted to provide a case population of 300 ; a response rate of $63.3 \%$. Of the 174 non-participants, 131 were pain free and 43 were unwilling to participate. A response rate of $69.4 \%$ was achieved in recruitment of controls; with 107 subjects unwilling to participate and 25 having knee pain. Table 1 shows demographic details of the study subjects and the total population surveyed. The cases were slightly older than the total knee pain positive population and had a higher female to male ratio $(1.8: 1 v 1.2: 1)$. They were similar with respect to body mass index but were more disabled based on SF-36 physical function scores. The control group were slightly older than the total knee pain negative group surveyed but were similar with respect to BMI and disability. The mean age of the cases was similar to that of the control group (61.3, SD 10.4 compared with 60.8 , SD 11.0). 
Table 3 Association of WOMAC pain score with anxiety and depression scores, voluntary quadriceps strength (MVC), quadriceps activation, and radiographic score. Values are adjusted for age, sex, and BMI in addition to variables shown using multiple linear regression. For bilateral variables, the worst value from either limb has been used in analysis

\begin{tabular}{|c|c|c|c|c|}
\hline & Coefficient & Standard error & $t$ & $p$ Value \\
\hline Constant & 4.64 & 2.11 & & \\
\hline Anxiety & 0.04 & 0.06 & 0.69 & 0.49 \\
\hline Depression & 0.27 & 0.07 & 3.66 & $<0.005$ \\
\hline MVC $(\mathrm{kgF})$ & -0.10 & 0.02 & -3.90 & $<0.005$ \\
\hline Activation (\%) & -0.03 & 0.01 & -3.01 & $<0.005$ \\
\hline \multirow[t]{2}{*}{ Radiographic score } & 0.15 & 0.06 & 2.50 & 0.13 \\
\hline & $\begin{array}{l}\text { Degrees of } \\
\text { freedom }\end{array}$ & Sum of squares & \multicolumn{2}{|c|}{ Mean squares } \\
\hline Regression & 8 & 1225.67 & \multicolumn{2}{|l|}{153.21} \\
\hline Residual & 221 & 1523.03 & \multicolumn{2}{|l|}{6.89} \\
\hline Total & 229 & 2748.70 & & \\
\hline
\end{tabular}

The model has an adjusted $r^{2}$ of 0.43 .

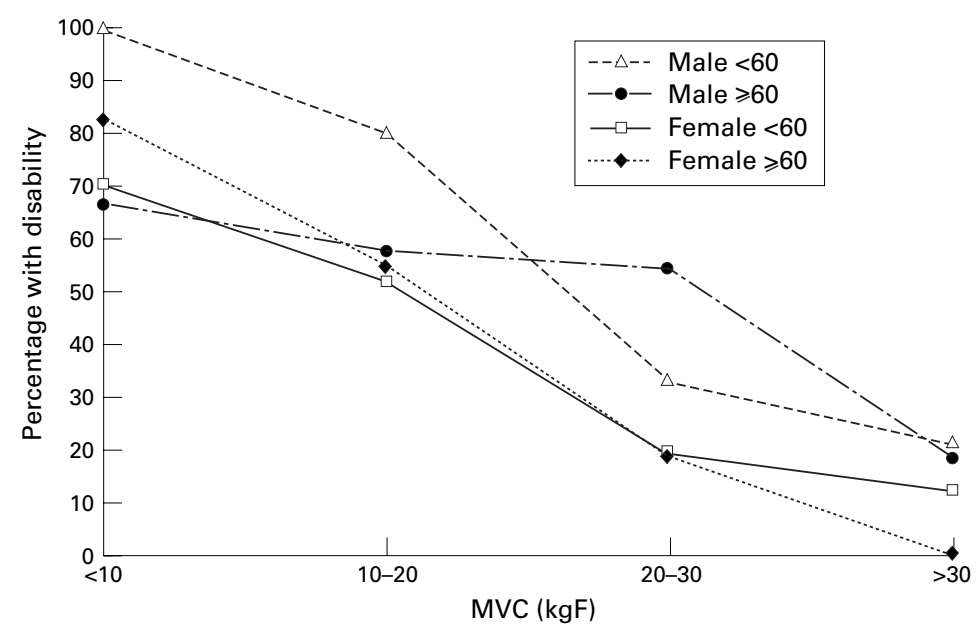

Figure 4 Percentage of knee pain positive subjects with disability (WOMAC function score $>19$ ) by level of quadriceps strength (lowest value for each subject for right or left knee). Results are presented separately for men aged 60-80 $(n=63)$, men aged 40-59 $(n=42)$, women aged 60-80 $(n=109)$ and women aged 40-59 $(n=84)$.

PAIN

Quadriceps strength and activation

Figure 1 shows the mean values for quadriceps strength. Values for right and left legs were similar. Quadriceps strength was significantly lower in those with knee pain compared with controls (right quadriceps: 22.6, 95\% CI 21.1, 24.0 versus 30.7 , $95 \%$ CI 29.2 , 32.2; $\mathrm{p}<0.005$ ). Activation was also significantly lower in those with pain (right quadriceps: $77.1,95 \%$ CI 74.0 , 80.4 versus $93.5,95 \%$ CI $91.2,95.9 ; \mathrm{p}<0.005)$. By correcting for activation (that is, assuming $100 \%$ activation), the difference in predicted strength was less though still statistically significant (right quadriceps: 30.0, 95\% CI28.3, 31.6 versus 33.3, 95\% CI 31.7, 34.8; $\mathrm{p}<0.005)$. For subsequent analysis, MVC data has been divided into intervals of $10 \mathrm{kgF}$. One value for MVC is given for each subject being the lowest of the two values from right and left limbs. Some $21.7 \%$ of subjects with knee pain have strengths of less than $10 \mathrm{kgF}$ compared with $3.7 \%$ of controls. Only $14.4 \%$ of knee pain positive subjects have strengths $>30 \mathrm{kgF}$ compared with $35 \%$ of controls.

Values for quadriceps activation have been divided into four intervals. As with MVC, quoted values are the lowest for each subject. Some $44.9 \%$ of subjects with knee pain activate less than $71 \%$ compared with $15.7 \%$ of controls. Ninety subjects had levels of activa- tion of more than $100 \%,(8.6 \%$ of cases and $22.2 \%$ of controls).

\section{Radiographic score}

Intraobserver reproducibility was high for all features $(\kappa>0.75)$ with the exception of patellofemoral sclerosis $(\kappa=0.58)$. Radiographic score has been divided into four levels. One value is presented for each subject; being the highest score from right and left knees. Figure 2 shows the corresponding percentage of subjects with pain for each level. Although knee pain is most common in subjects with scores of $\geqslant 4$, subjects with normal radiographs also have a relatively high frequency of pain.

\section{Anxiety and depression}

Mean HAD score for depression was higher in those with knee pain compared with those without pain $(4.9,95 \%$ CI $4.6,5.3$ versus 2.9 , $95 \%$ CI $2.6,3.1 ; \mathrm{p}<0.005)$. Values for anxiety were also significantly higher in the knee pain positive group $(7.1,95 \% \mathrm{CI} 6.6,7.6$ versus 5.4 , $95 \%$ CI 5.1, 5.8; p<0.005). Both anxiety and depression, defined as HAD score $\geqslant 8$, occurred significantly more frequently in subjects with knee pain (fig 3).

\section{Multivariate analysis}

Table 2 shows odds ratios (with 95\% confidence intervals) for presence of knee pain. In addition to those variables listed, odds ratios have been adjusted for age, sex, and body mass index. Depression, quadriceps strength, activation, and radiographic score are all associated with increased odds for knee pain. For quadriceps strength, the association is particularly apparent for the lowest strength values, with quadriceps strengths of $10 \mathrm{kgF}$ or less associated with a 19-fold increase in odds for pain. A similar result is obtained if radiographic score is substituted with maximum grade for osteophyte or joint space narrowing. Substituting worst values with values for right knee and right quadriceps does not significantly change the result.

\section{Severity of pain}

Table 3 shows the factors associating with severity of pain (WOMAC pain score). As with the previous analysis, adjustments have been made for age, sex, and BMI in addition to those listed. Depression, quadriceps strength, and activation are all independently associated with pain, but radiographic score is not. This regression explains $42.6 \%$ of the variance in WOMAC pain scores.

\section{DISABILITY}

Knee pain positive group

Disability (WOMAC function score $>19$ ) in the knee pain group, was inversely associated with quadriceps strength (fig 4). The two strongest MVC levels have been amalgamated as numbers in these are small when restricted to knee pain positive subjects.

Table 4 shows the adjusted odds ratios for presence of disability (WOMAC function score $>19$ ) in the knee pain positive group. Depression and quadriceps weakness show increased 
Table 4 Association of disability (WOMAC function score >19) with anxiety, depression, voluntary quadriceps strength (MVC), quadriceps activation, and radiographic score in subjects with knee pain. Odds ratios have been calculated using logistic regression and are adjusted for age, sex, and BMI in addition to the variables shown. For bilateral variables, the worst value from either limb has been used in analysis

\begin{tabular}{|c|c|c|c|c|}
\hline & \multicolumn{2}{|l|}{ Disability } & \multirow[b]{2}{*}{ Odds ratio } & \multirow[b]{2}{*}{ 95\% Confidence intervals } \\
\hline & yes $(\%)$ & no (\%) & & \\
\hline \multicolumn{5}{|l|}{ Anxiety } \\
\hline$<8$ & $49(35.3)$ & $90(64.7)$ & 1 & $\star$ \\
\hline$\geqslant 8$ & $57(63.3)$ & $33(36.7)$ & 1.91 & $0.89,4.05$ \\
\hline \multicolumn{5}{|c|}{ Depression } \\
\hline$<8$ & $71(38.0)$ & $116(62.0)$ & 1 & $\star$ \\
\hline$\geqslant 8$ & $35(83.3)$ & $7(16.7)$ & 6.15 & $2.10,17.98$ \\
\hline \multicolumn{5}{|c|}{ MVC (kgF) } \\
\hline$>30$ & $4(12.9)$ & $27(87.1)$ & 1 & $\star$ \\
\hline $20-30$ & $18(26.5)$ & $50(73.6)$ & 1.48 & $0.37,5.93$ \\
\hline $10-20$ & $50(57.5)$ & $37(42.5)$ & 4.88 & $1.18,20.14$ \\
\hline$\leqslant 10$ & $34(79.1)$ & $9(20.9)$ & 8.23 & $1.53,44.38$ \\
\hline \multicolumn{5}{|c|}{ Activation (\%) } \\
\hline$>90$ & $13(25.5)$ & $38(74.5)$ & 1 & $\star$ \\
\hline $71-90$ & $25(32.1)$ & $53(67.9)$ & 1.07 & $0.42,2.75$ \\
\hline$\leqslant 70$ & $68(68.0)$ & $32(32.0)$ & 2.81 & $1.01,7.80$ \\
\hline \multicolumn{5}{|c|}{ Radiographic score } \\
\hline $0-1$ & $32(50.8)$ & $31(49.2)$ & 1 & \\
\hline $2-3$ & $36(64.3)$ & $20(35.7)$ & 0.79 & $0.29,2.14$ \\
\hline$\geqslant 4$ & $55(50.0)$ & $55(50.0)$ & 0.87 & $0.46,2.16$ \\
\hline
\end{tabular}

${ }^{\star}$ Denotes a significant trend test $(\mathrm{p}<0.05)$.

Table 5 Association of WOMAC function score with WOMAC pain scores, anxiety and depression scores, voluntary quadriceps strength (MVC), quadriceps activation, and radiographic score in subjects with knee pain. Values are adjusted for age, sex, and BMI in addition to variables shown using multiple linear regression. For bilateral variables, the worst value from either limb has been used in analysis

\begin{tabular}{lllll}
\hline & Coefficient & Standard error & $t$ & p Value \\
\hline Constant & -6.06 & 0.53 & 3.23 & 0.30 \\
WOMAC pain score & 0.44 & 0.20 & 2.11 & $<0.005$ \\
Anxiety & 0.43 & 0.18 & 1.17 & 0.006 \\
Depression & 2.15 & 0.07 & -1.62 & 0.036 \\
MVC (kgF) & -0.11 & 0.02 & -2.20 & 0.11 \\
Activation (\%) & -0.05 & 0.16 & 0.19 & 0.03 \\
Radiographic score & 0.03 & 5.58 & -1.09 & 0.85 \\
& Degrees of & Sum of squares & Mean squares \\
Regression & freedom & & \multicolumn{2}{l}{} \\
Residual & 9 & 26494.29 & 2943.81 & \\
Total & 220 & 10412.49 & 47.33 & \\
\hline
\end{tabular}

The model has an adjusted $r^{2}$ of 0.71 .

Table 6 Association of disability (SF-36 function score <90) with anxiety, depression, voluntary quadriceps strength (MVC), quadriceps activation, and radiographic score in subjects without pain. Odds ratios have been calculated using logistic regression and are adjusted for age, sex, and BMI in addition to the variables shown. For bilateral variables, the worst value from either limb has been used in analysis

\begin{tabular}{|c|c|c|c|c|}
\hline & \multicolumn{2}{|l|}{ Disability } & \multirow{2}{*}{$\begin{array}{l}\text { Odds } \\
\text { ratio }\end{array}$} & \multirow[b]{2}{*}{$95 \%$ Confidence intervals } \\
\hline & yes $(\%)$ & no (\%) & & \\
\hline \multicolumn{5}{|l|}{ Anxiety } \\
\hline$<8$ & $72(46.5)$ & $83(53.5)$ & 1 & \\
\hline$\geqslant 8$ & $35(62.5)$ & $21(37.5)$ & 2.04 & $0.95,4.36$ \\
\hline \multicolumn{5}{|c|}{ Depression } \\
\hline$<8$ & $97(48.5)$ & $101(51.5)$ & 1 & $\star$ \\
\hline$\geqslant 8$ & $10(90.9)$ & $1(9.1)$ & 8.27 & $0.91,83.94$ \\
\hline \multicolumn{5}{|c|}{ MVC (kgF) } \\
\hline$>40$ & $6(24.0)$ & $19(76.0)$ & 1 & \\
\hline $30-40$ & $19(43.2)$ & $25(56.8)$ & 3.04 & $0.86,10.71$ \\
\hline $20-30$ & $46(54.8)$ & $38(45.2)$ & 3.77 & $1.02,13.91$ \\
\hline$\leqslant 20$ & $36(62.1)$ & $22(37.9)$ & 4.98 & $1.08,22.97$ \\
\hline \multicolumn{5}{|c|}{ Activation (\%) } \\
\hline$>90$ & $38(40.4)$ & $56(59.6)$ & 1 & \\
\hline $71-90$ & $46(57.5)$ & $34(42.5)$ & 1.57 & $0.76,3.24$ \\
\hline$\leqslant 70$ & $23(62.2)$ & $14(37.8)$ & 1.40 & $0.51,3.80$ \\
\hline \multicolumn{5}{|c|}{ Radiographic score } \\
\hline $0-1$ & $44(48.9)$ & $46(51.1)$ & 1 & \\
\hline $2-3$ & $32(43.2)$ & $42(56.8)$ & 0.52 & $0.24,1.10$ \\
\hline$\geqslant 4$ & $31(66.0)$ & $16(34.0)$ & 0.90 & $0.37,2.22$ \\
\hline
\end{tabular}

${ }^{\star}$ Denotes a significant trend test $(\mathrm{p}<0.05)$.

odds for disability. Similar results are obtained if radiographic score is substituted with maximum grade of osteophyte or with maximum grade of joint space narrowing. If SF-36 scores are used to define disability $(<55)$, the result is again not significantly altered.

Table 5 shows the corresponding results if disability is treated as a continuous variable. Factors have been adjusted for age, sex, and $\mathrm{BMI}$, in addition to the factors presented. This regression model explains $71.0 \%$ of the variance in WOMAC function scores.

Knee pain negative group

If disability in this group is defined by the median value for SF-36 physical function $(<90)$, independent associations with disability are suggested for quadriceps strength $\leqslant 20 \mathrm{kgF}$ (odds ratio 4.98, CI 1.08, 22.97 and depression (odds ratio 8.27, CI 0.91, 83.94) (table 6).

\section{Discussion}

We have examined quadriceps strength, quadriceps activation, structural change, anxiety and depression in subjects with and without knee pain. Quadriceps weakness is strongly associated with knee pain; this being particularly marked for strengths of $10 \mathrm{kgF}$ or less. While there have been data on hospital referred knee osteoarthritis, ${ }^{28}{ }^{29}$ there are few similar reports on knee pain in a community sample. One study, while not part of its primary comparison, found strength to be similar in subjects with and without knee pain. ${ }^{15}$ Numbers, however, were small and values from right and left limbs were averaged. Patient positioning was also different, with subjects reclining rather than sitting. A more recent study measured isokinetic rather than isometric strength and found subjects with symptomatic OA to be weaker than those with asymptomatic OA. ${ }^{30}$ Pain during strength testing was not assessed in our study and could have caused an apparent reduction in quadriceps strength. As the relation persisted after correction for incomplete activation, such an effect can be discounted.

This study has demonstrated incomplete activation in subjects with knee pain. This has not been assessed before in the community, though studies have reported incomplete activation in hospital referred patients with knee OA. ${ }^{31} 32$ Pain during strength testing may cause incomplete activation, as may the presence of an acute effusion. ${ }^{18}$ Pain was not specifically assessed during measurements in this study, and being community based very few subjects had any clinical evidence of effusion. Even among the pain free group in our study, however, incomplete activation was apparent though less marked. Previous work has demonstrated an association between structural change and arthrogenic inhibition in the absence of pain that may explain the current findings. ${ }^{33}$ Incomplete activation may, however, also occur in "normal" subjects. ${ }^{34}$ Activation appears less important when investigated using multivariate analysis. An association between activation and psychological outlook has been suggested from work in fibromyalgia, ${ }^{35}$ and may to some extent explain this finding. It is not possible to differentiate between arthrogenous muscle inhibition and lack of voluntary 
effort. It is, however, tempting to speculate that the latter may be important in this study because of the association with psychological status.

A proportion of subjects in this study demonstrated more than $100 \%$ quadriceps activation. It is possible that the technique used underestimated the degree of incomplete activation. It may also relate to the relation between twitch height and activation being non-linear as has been reported in the literature. ${ }^{35}$ This finding was not confined to the strongest subjects and it seems unlikely to have had a major impact on the differences in activation between the groups.

The association between psychological factors and pain has been described in hospital referred populations. ${ }^{16}$ This study demonstrates a similar association in the community. The findings in terms of radiographic osteoarthritic change emphasise the well recognised disparity with symptoms, because it was only with higher scores that a strong association with pain was apparent. The association will, however, depend on the radiographic techniques used. To maximise the association, the patellofemoral compartment has been included, ${ }^{36}$ and has been imaged using the skyline view. ${ }^{37}$ Although most researchers favour the use of osteophyte to define osteoarthritis, the best method for grading severity is less clear. We used a global score similar to that used in the Bristol community study, ${ }^{15}$ but with a standard atlas. ${ }^{27}$ Division of global score was chosen to provide uniform groups with the exception of grade 0 , which was a small group. It is possible that such division may have underestimated the importance of structural change. However, as substitution with grade of maximum osteophyte and joint space narrowing produced similar results, this seems unlikely. The lack of association with pain when examined in a linear model supports this view.

Quadriceps weakness is associated with disability in subjects with knee pain. This association has been reported previously in a community sample. ${ }^{15}$ While the study is not directly comparable, in that it used a slightly different method of strength assessment and an alternative disability questionnaire, the association appears stronger in the Bristol population. This discrepancy may, in part, be explained by the inclusion of quadriceps activation and psychological factors in the current study. Incomplete activation is more marked in those with disability but does not fully explain the association with strength. Including confounders in the analysis does not weaken the association with muscle strength, nor does defining disability with a less disease specific instrument (SF-36).

The relations observed in this study cannot be confirmed as causal. Theoretically, we believe that quadriceps strength is important in disability. Severe levels of disability or inactivity are known to provoke muscle wasting and may contribute to the decline in strength reported in elderly populations. ${ }^{1011}$ This study population, however, were neither all inactive or elderly. As the quadriceps mechanism is of key importance in terms of walking, standing, and using stairs, muscle weakness may directly cause impaired function. It may also explain the large increase in odds for disability in those with particularly weak muscles $(<10 \mathrm{kgF})$. There is some evidence to suggest that weakness in the elderly may predate functional problems ${ }^{12}$; with improvement seen after muscle strengthening programmes. ${ }^{38}$ Why people with knee pain or knee OA should develop quadriceps weakness is unclear. Structural change particularly at the patellofemoral compartment, may change the biomechanical relation. ${ }^{39}$ Alternatively structural change or inflammation may provoke arthrogenic inhibition and resultant wasting. ${ }^{40}$ The findings of this study may have major implications in terms of the elderly population in general as well as to those with knee OA. Further work is needed to elucidate the temporal relation between strength and pain and disability.

This study in agreement with the Bristol survey, ${ }^{15}$ has found no major effect of radiographic severity on disability. It is possible that the grading method previously discussed may have contributed to this though again the consistency of results makes this unlikely. To infer from this that the underlying pathological process is unimportant in terms of functioning of the knee and lower limb, would nevertheless seem unreasonable. Perhaps current imaging techniques do not accurately reflect the severity of structural change. Radiographic features, while acting as a marker for the presence of disease, may have little to do with ongoing disease activity.

Certain caveats may apply to this study. Selection bias cannot be discounted because response rates were lower than is often considered acceptable in a case-control study. For cases this was largely because of lack of current pain and hence unavoidable. While effort was made to ensure that cases were representative of the knee pain population, subjects tended to be older, and hence potentially more disabled than the knee pain positive population as a whole. As control subjects were matched by age, this should not have contributed to between group differences. Refusal to participate was the main factor for non-recruitment of controls and, given the need for radiographs and muscle activation measurement, is perhaps not surprising. If this unwillingness represented a differing state of health to recruited controls, then bias would be anticipated. The similarity with respect to disability and obesity, while only crude indicators, argue against this. The possibility of bias in radiographic attainment must be considered because $20 \%$ did not have radiographs, and proportionally more of these were from the control group. Age representation was similar to subjects who did have radiographs and this is again unlikely to have exerted a major effect.

The analysis of bilateral variables is problematic. Methods previously used, including summation of radiographic scores and averaging quadriceps strength, may underestimate the impact of asymmetrical severity. Analysing results from one leg alone ignores the possibility 
of a unilateral problem. For this study the worst value whether right or left was used. Although this may have overestimated the importance of these variables, it should not have favoured one in particular. As single variables such as anxiety and depression remained important, such an effect can probably be discounted. Methods are now becoming available to deal with bilateral variables, ${ }^{41}$ but as the outcome variables of pain and disability were examined as single variables in this study, such techniques were not applied.

The transformation of continuous into categorical data was necessary to meet assumptions of the statistical tests, but required more complex models. The possibility that the divisions selected may have underestimated the importance of a particular variable cannot be discounted. Nevertheless the consistency of findings makes this unlikely. The definition of disability using a median value as a cut off is clearly arbitrary. As there is no agreed figure for WOMAC or SF-36 in such a situation, this definition was chosen to ensure adequate numbers for logistic modelling. The consistency of results when modelled as a continuous variable, suggests that the definition did not significantly underestimate the importance of the factors examined.

In summary the association of quadriceps strength with pain and disability in the community has been confirmed. This association remains when adjusted for psychological factors and muscle activation. Radiographic severity is weakly associated with pain but not with disability. These findings may have important implications for those with knee OA and knee pain, particularly in terms of therapeutic and preventative strategies.

The authors are extremely grateful to the general practitioners, staff and in particular patients of the Stenhouse Medical Centre Arnold and the Calverton Surgery for their support and cooperation. This research was funded by the Arthritis and Rheumatism Council for Research to whom we are indebted.

1 Kellgren JH, Lawrence JS. Osteo-arthrosis and disk degeneration in an urban population. Ann Rheum Dis $1958 ; 17: 388-96$

2 Felson DT, Naimark A, Anderson JJ, Kazis L, Castelli W, Meenan RF. The prevalence of knee osteoarthritis in the elderly: the Framingham osteoarthritis study. Arthritis Rheum 1987;30:914-18.

3 Badley EM, Tennant A. Disablement associated with rheumatic disorders in a British population: problems with activities of daily living and level of support. Br J Rheumatol 1993;32:601-8.

4 Hammerman D. Clinical implications of osteoarthritis and ageing. Ann Rheum Dis 1995;54:82-5.

5 Lawrence JS, Bremner JM, Bier F. Osteo-arthrosis: prevalence in the population and relationship between symptoms and x-ray changes. Ann Rheum Dis 1966;25:1-23.

6 Anderson JJ, Felson DT. Factors associated with osteoarthritis of the knee in the first national health and nutrition thritis of the knee in the first national health and nutrition
examination survey (HANES 1). Evidence for an associaexamination survey (HANES 1). Evidence for an associa-
tion with overweight, race and physical demands of work. tion with overweight, race and phy
Am J Epidemiol 1988;128:179-89.

7 Felson DT, Zhang Y, Anthony JM, Naimark A, Anderson JJ. Weight loss reduces the risk for symptomatic knee osteoarthritis in women. Ann Intern Med 1992;116:535-9.

8 Cooper C, McAlindon TE, Coggon D, Egger P, Dieppe PA. Occupational activity and osteoarthritis of the knee. Ann Rheum Dis 1994;53:90-3.

9 Hadler NM. Knee pain is the malady-not osteoarthritis. Ann Intern Med 1992;116:598-9.

10 Young A, Stokes M, Crowe M. Size and strength of the quadriceps muscle of old and young women. Eur J Clin Invest 1984;14:282-7.

11 Young A, Stokes M, Crowe M. The size and strength of the quadriceps muscles of old and young men. Clin Physiol 1985;5:145-54

12 Lipsitz LA, Nakajima I, Gagnon M, Hirayama T, Connelly CM, Izumo H. Muscle strength and fall rates among residents of Japanese and American nursing homes: an dents of Japanese and American nursing homes: an
international cross-cultural study. J Am Geriatr Soc 1994; international.
13 Lankhorst GJ, Van de Stadt RJ, Van der Korst JK. The relationships of functional capacity, pain, and isometric and sokinetic torque in osteoarthrosis of the knee. Scand J Rehab Med 1985;17:167-72.

14 Dekker J, Tola P, Aufdemkampe G, Winckers M. Negative affect, pain and disability in osteoarthritis patients: the mediating role of muscle weakness. Behav Res Ther 1993; 31:203-6.

15 McAlindon TE, Cooper C, Kirwan JR, Dieppe PA. Determinants of disability in osteoarthritis of the knee. Ann Rheum Dis 1993;52:258-62.

16 Summers MN, Haley WE, Reveille JD, Alarcón G. Radiographic assessment and psychological variables as predictors of pain and functional impairment in osteoarthritis of the knee or hip. Arthritis Rheum 1988;31:204-9.

17 Stokes M, Young A. The contribution of reflex inhibition to arthrogenous muscle weakness. Clin Sci 1984;67:7-14.

18 Spencer JD, Hayes KC, Alexander IJ. Knee joint effusion and quadriceps reflex inhibition in man. Arch Phys Med Rehabil 1984;65:171-7.

19 Jones DW, Jones DA, Newham DJ. Chronic knee effusions and aspiration: the effect on quadriceps inhibition. Br J Rheumatol 1987;26:370-4

20 O'Reilly SC, Muir KR, Doherty M. Screening for knee pain in osteoarthritis: which question? Ann Rheum Dis 1996;55:931-3

21 Bellamy N, Buchanan WW, Goldsmith $\mathrm{CH}$, Campbell J. Validation study of WOMAC: a health status instrument for measuring clinically-important patient-relevant outcomes following total hip or knee arthroplasty in osteoarthritis. J Orthop Rheumatol 1988;1:95-108.

22 Brazier JE, Harper R, Jones NM, O'Cathain A, Thomas KJ, Usherwood T, et al. Validating the SF-36 health survey questionnaire: new outcome measure for primary care. BMJ 1992;305:160-5.

23 Zigmond AS, Snaith RP. The hospital anxiety and depression scale. Acta Psychiatr Scand 1983;67:361-70.

24 Tornvall G. Assessment of physical capabilities with special reference to the evaluation of maximum voluntary isometric muscle strength. Acta Physiol Scand 1963;58 (suppl 201):1-102.

25 Rutherford OM, Jones DA, Newham DJ. Clinical and experimental application of the percutaneous twitch superimposition technique for the study of human muscle activation. J Neurol Neurosurg Psychiatr 1986;49:128891

26 Bigland-Ritchie B, Furbish F, Woods JJ. Neuromuscular transmission and muscle activation in human post-fatigue ischaemia. J Physiol 1986;377:76P.

27 Burnett S, Hart DJ, Cooper C, Spector TD. A radiographic atlas of osteoarthritis. London: Springer Verlag, 1994.

28 Nordesjö LO, Nordgren B, Wigren A, Kolstad K. Isometric strength and endurance in patients with severe rheumatoid arthritis or osteoarthrosis in the knee joints: a comparative study in healthy men and women. Scand J Rheumatol $1983 ; 12: 152-6$

29 Ekdahl C, Andersson SI, Svensson B. Muscle function of the lower extremities in rheumatoid arthritis and osteoarthrosis: a descriptive study of patients in a primary health care district. J Clin Epidemiol 1989;42:947-54

30 Slemenda C, Brandt KD, Heilman DK, Mazzuca S, Braunstein EM, Katz BP, et al. Quadriceps weakness and osteoarthritis of the knee. Ann Intern Med 1997;127:97104.

31 Hurley MV, Newham DJ. The influence of arthrogenous muscle inhibition on quadriceps rehabilitation of patients with early, unilateral osteoarthritic knees. Br J Rheumatol 1993;32:127-31.

32 Jones A, Regan M, Doherty M. Determinants of arthrogenic inhibition in knee osteoarthritis. Br J Rheumatol 1995;34: (suppl 1)256.

33 Young A. Current issues in arthrogenous inhibition. Ann Rheum Dis 1993;52:829-34.

34 Jacobsen S, Wildschiodtz G, Danneskiold-Samsoe B. Isokinetic and isometric muscle strength combined with trancutaneous electrical muscle stimulation in primary fibromyalgia syndrome. J Rheumatol 1991;18:1390-3.

35 Norregaard J, Bülow PM, Vestergaard-Poulsen P, Thomsen C, Danneskiold-Samsoe B. Muscle strength, voluntary activation and cross-sectional muscle area in patients with fibromyalgia. Br J Rheumatol 1995;34:925-31

36 McAlindon TE, Snow S, Cooper C, Dieppe PA. Radiographic patterns of osteoarthritis of the knee joint in the community: the importance of the patellofemoral joint. Ann Rheum Dis 1992;51:844-9.

37 Cicuttini FM, Baker J, Hart DJ, Spector TD. Choosing the best method for radiological assessment of patellofemoral osteoarthritis. Ann Rheum Dis 1996;55:134-6.

38 Fiatarone MA, Marks EC, Ryan ND, Meredith CN, Lipsitz LA, Evans WJ. High-intensity strength training in nonagenarians: effects on skeletal muscle. JAMA 1990; 263:3029-34.

39 Reilly DT, Martens M. Experimental analysis of the quadriceps muscle force and patello-femoral joint reaction force for various activities. Acta Orthop Scand 1972;43:126-37.

0 Young A, Stokes M, Iles JF. Effects of joint pathology on muscle. Clin Orthop 1987;219:21-7.

41 Zhang Y, Glynn RJ, Felson DT. Musculoskeletal disease research: should we analyze the joint or the person? J Rheumatol 1996;23:1130-4. 